International Journal of Medical Sciences ISSN 1449-1907 www.medsci.org 2006 3(1):1-6

Research paper

\title{
Polysaccharides from the root of Angelica sinensis protect bone marrow and gastrointestinal tissues against the cytotoxicity of cyclophosphamide in mice
}

\author{
Marco K. C. Hui, William K. K. Wu, Vivian Y. Shin, Wallace H. L. So and Chi Hin Cho \\ Centre of Infection and Immunology and Department of Pharmacology, Faculty of Medicine, The University of Hong Kong, Hong \\ Kong, China
}

Corresponding address: Prof. C.H. Cho, Department of Pharmacology, The University of Hong Kong, 21 Sassoon Road, Hong Kong, China. Email: chcho@hkusua.hku.hk Telephone: 852-2819-9250 Fax: 852-2817-0859

Received: 2005.09.08; Accepted: 2005.12.15; Published: 2006.01.01

Cyclophosphamide (CY) is a cytostatic agent that produces systemic toxicity especially on cells with high proliferative capacity, while polysaccharides from Angelica sinensis (AP) have been shown to increase the turnover of gastrointestinal mucosal and hemopoietic stem cells. It is not known whether AP has an effect on CY-induced cytotoxicity on bone marrow and gastrointestinal tract. In this study, we assessed the protective actions of AP on CY-induced leukopenia and proliferative arrest in the gastroduodenal mucosa in mice. Subcutaneous injection of CY (200 mg/kg) provoked dramatic decrease in white blood cell (WBC) count and number of blood vessels and proliferating cells in both the gastric and duodenal mucosae. Subcutaneous injection of AP significantly promoted the recovery from leukopenia and increased number of blood vessels and proliferating cells in both the gastric and duodenal tissues. Western blotting revealed that CY significantly down-regulated the protein expression of vascular endothelial growth factor (VEGF), CMyc and ornithine decarboxylase (ODC) in gastric mucosae but had no effect on epidermal growth factor (EGF) expression. AP also reversed the dampening effect of CY on VEGF expression in the gastric mucosa. These data suggest that AP is a cytoprotective agent which can protect against the cytotoxicity of CY on hematopoietic and gastrointestinal tissues when the polysaccharide is co-administered with CY in cancer patients during treatment regimen.

K ey words: A ngelica sinensis, polysaccharides, cyclophosphamide, leukopenia, gastrointestinal tract, angiogenesis

\section{Introduction}

The major side effect of anticancer drugs, e.g. cyclophosphamide, is the non-specific cytostatic action on normal healthy cells, especially those with high proliferating capacity like the hematopoietic and GI tissues [1]. The extensive death of the immune cells results in leukopenia which severely weakens the immune system of cancer patients and therefore greatly increases the chance of disseminated infections which could be fetal. As a result, drug-free period is always clinically necessary in cancer patients receiving chemotherapy, so as to allow their immune systems to restore function [2]. On the other hand, the death of GI cells breaks down the physical defence of GI system in the host who will become more susceptible to antigen originated from GI systems and therefore further increases death rate due to opportunistic infection [3]. In addition, emesis due to the release of serotonin from enterochromaffin cells is also discouraging to cancer patients [4]. All of these are the main reasons for discontinuation of cancer chemotherapy, which lowers the chance of a successful and complete treatment regimen.

Angelica sinensis, also known as Danggui, has been used as a medicinal herb in China for thousands of years and renowned for its therapeutic effects on gynecological disorders, such as amenorrhea and menopause [5]. Recent pharmacological studies demonstrated the polysaccharides fraction of Angelica sinensis had radio-protective effects in irradiated mice through modulation of proliferative response of hemopoietic stem cells [6]. Concerning gastrointestinal system, $\mathrm{AP}$ was known to be protective against ethanol- or indomethacin-induced mucosal damage [7]. It was also reported that Angelica sinensis crude extract increased the proliferation of gastric epithelial cells through modulation of several proliferation-related genes, including EGF, ODC, and c-Myc [8-10]. In addition to the effect on hemopoietic and gastrointestinal tissues, AP was also shown to possess anti-tumor effect [11, 12]. However, the protective effect of AP on CY-induced cytotoxicities in both the hemopoietic and gastrointestinal tissues was undefined. Any of these actions would extend the therapeutic application of $\mathrm{CY}$ in cancer patients in which the herb could be used together with the cytotoxic agent in cancer therapeutic regimen.

In the present study, we investigated whether AP could protect the bone marrow and the gastrointestinal tissues from the cytotoxicity of $\mathrm{CY}$ in mice. We also profiled the changes of the expression of growth factors in gastric tissues in response to the damage by $\mathrm{CY}$ and protection by AP.

\section{Materials and Methods}

Chemicals and Reagents

All chemicals and reagents were of analytical grade and were purchased from Sigma (Sigma-Aldrich, St. Louis, $\mathrm{MO}, \mathrm{USA}$ ) unless otherwise specified.

\section{Preparation of Angelica sinensis Polysaccharides}

The roots of Angelica sinensis (Oliv.) Diels, Danggui, were purchased from Minxian County, Gansu Province, China. Polysaccharides fraction was isolated by the ethanol precipitation method as described by Cho et al [7] and modified by Ye et al. [10]. Briefly, one hundred grams of roots of Angelica were boiled for three four-hour periods with water for a total of 12 hours. After each four-hour period of boiling, the water extract was collected and the 
residue was boiled again with water for another four-hour period. All extracts were finally pooled and mixed with a concentrated ethanol solution (final concentration 75\% $\mathrm{v} / \mathrm{v})$ to precipitate the polysaccharide-enriched fraction. Two kinds of high performance liquid chromatography (HPLC) methods including the high performance anion exchange and the gel filtration chromatography, respectively [13], were employed to concentrate and determine the molecular size of the polysaccharide-rich fraction. The molecular sizes of polysaccharides were determined in HPLC (gel filtration column, Biosep SECS3000, Phenomenex, USA; mobile phase $0.15 \mathrm{~mol} / \mathrm{L} \mathrm{NaCl}$ solution; detector wavelength $220 \mathrm{~nm}$ ) combined with the phenol-sulfuric acid method [14, 15]. The amounts of uronic acids and proteins were also determined [16, 17].

The Angelica polysaccharide fraction was found to consist of 5 main polysaccharide sub-fractions with the following moleculard weights: >670.00, 433.72, 167.55, 82.10 and $15.54 \mathrm{kD}$ respectively. The total extracted fraction consisted of $97 \%$ carbohydrates (about 30\% of them uronic acids) and 3\% proteins. This polysaccharideenriched fraction from Angelica sinensis (AP) was dissolved in normal saline $(0.9 \%, \mathrm{w} / \mathrm{v}, \mathrm{NaCl})$ before subcutaneous injection to animals.

\section{Experimental animals and drug administration}

This study was conducted with the consent of the Committee on the Use of Live Animals in Teaching and Research of the University of Hong Kong. Male ICR mice (weighing 25-30 g) were reared on a standard laboratory diet (Ralston Purina, Chicago, Illinois, USA) and given tap water ad libitum. Mice were randomly allocated into 5 treatment groups ( $\mathrm{n}=8-15$ in each group) which were subject to a 14-day treatment. Group 1 was the normal untreated control (Nor) while groups 2 to 5 received a single dose of CY $200 \mathrm{mg} / \mathrm{kg}$ daily by subcutaneous injection on day 0 and day 7 . In addition, group 2 (NS) mice received daily dose of normal saline while groups 3 to 5 mice received daily dose of AP at 5 (AP5), 10 (AP10) or 25 (AP25) $\mathrm{mg} / \mathrm{kg}$, respectively. Mice were sacrificed on day 14 and the gastric and duodenal tissues were collected for biochemical and histological assessments.

\section{Assessment of white blood cell (WBC) count}

Blood samples were collected from the tail arteries on day $0,4,7,11$ and 14 to monitor the toxicity of $\mathrm{CY}$ on bone marrow by measuring WBC number in the peripheral blood. Twenty microliters of blood was mixed with 380ul of Randolph's solution. WBC counting was then performed by using an improved Neubauer hematocytometer (Reichert, U.S.A.).

\section{Assessment of angiogenesis}

Immunohistochemical staining of microvessels in the tissues of stomach and duodenum was performed by using von Willebrand factor antibody [18]. The prepared sections were incubated with $0.3 \% \mathrm{H}_{2} \mathrm{O}_{2}$ in methanol and then trypsinized in $0.1 \%$ trypsin for 30 minutes at room temperature followed by washing with $0.01 \mathrm{M}$ phosphatebuffered saline. The sections were then incubated for 1 hour with $1.5 \%$ normal goat serum, and subsequently incubated with polyclonal rabbit anti-human von Willebrand factor antibody at dilution of 1:500 in a humidified chamber overnight at $4{ }^{\circ} \mathrm{C}$. Endothelial cells of blood vessel were then visualized by applying the DAKOstaining system (LSAB kit, DAKO, Copenhagen,
Denmark). Blood vessels stained with the antibody to von Willebrand factor were counted with Leica image processing and analysis system at a 200x magnification (Q500IW, Leica Imaging Systems, Cambridge, UK).

\section{Assessment of cell proliferation}

To determine the number of proliferative cells, proliferating cell nuclear antigen (PCNA) in gastric and duodenal tissues was stained according to the method described by Kitajima et al. [19] with some modifications. Briefly, re-hydrated sections were immersed in $0.3 \% \mathrm{H}_{2} \mathrm{O}_{2}$ solution, followed by immersion in diluted normal serum for 1 hour in a humidified container at room temperature. They were incubated with anti-PCNA mouse monoclonal antibody (PC10, Santa Cruz, USA) in a humidified container at $4{ }^{\circ} \mathrm{C}$ overnight followed by a 45 -minute incubation in peroxidase-labeled streptavidin (from DAKO kit). Finally the sections were stained with diaminobenzidine $-\mathrm{H}_{2} \mathrm{O}_{2}$ solution at room temperature. The number of stained cells was counted under microscope (Q500IW, Leica Imaging Systems, Cambridge, UK) with a 400x magnification.

\section{Western blotting}

Protein expressions of VEGF, EGF, ODC and c-Myc in gastric tissues were assessed by Western blot analysis. Briefly, gastric tissues were homogenized $(100 \mathrm{mg} / \mathrm{ml})$ for 30 seconds in a radioimmune precipitation assay buffer (50 mM Tris- $\mathrm{HCl}, \mathrm{pH} 7.5,150 \mathrm{mM}$ sodium chloride, 0.5\% a-cholate, $0.1 \%$ sodium dodecyl sulphate (SDS), $2 \mathrm{mM}$ EDTA, $1 \%$ Triton X-100 and 10\% glycerol), containing $1.0 \mathrm{mM}$ phenylmethylsulfonyl fluoride and $1 \mu \mathrm{g} / \mathrm{ml}$ aprotinin. Samples were then centrifuged at $12,000 \mathrm{rpm}$ for 20 min at $4{ }^{\circ} \mathrm{C}$ and the supernatant containing total protein was denatured and separated by electrophoresis on a SDSpolyacrylamide gel (The percentage of the gel was 15\% for VEGF, $15 \%$ for EGF, $10 \%$ for ODC and $10 \%$ for c-Myc protein). The protein was then transferred to a nitrocellulose membrane (Bio Rad, Hercules, CA, USA) that was probed with primary antibody against VEGF (1:250, Santa Cruz, USA), EGF (1:250, Santa Cruz, USA), ODC (1:250, NeoMarkers, USA) or c-Myc (1:250, Santa Cruz, USA). Membranes were developed by using enhanced chemiluminescence (ECL) solution and exposed on X-ray film. Quantification of bands on the film was carried out by video densitometry (Gel Doc 1000, Bio Rad, Hercules, USA).

\section{Statistical Analysis}

Results are expressed as the mean \pm standard error (S.E.), and statistical comparisons were based on unpaired Student's $t$ test. A $p$-value of less than 0.05 was considered as statistically significant.

\section{Results}

\section{Effects of Angelica polysaccharides on the recovery from cyclophosphamide-induced leukopenia}

Subcutaneous administration of $\mathrm{CY}$ resulted in a significant drop in WBC number on day 4 and $11(80 \%$ and $88 \%$ respectively) in mice. Recovery of WBC count started on day 4 and day 11 in all treatment groups and returned back to the normal level on day 7 and day 14 in NS group. $\mathrm{AP}$ at all doses did not have any effect on peripheral WBC count in CY-treated mice on either day 4 or day 11 . However, the rate of recovery of WBC number in mice treated with AP $5 \mathrm{mg} / \mathrm{kg}$ was significantly increased. In 
NS group, the time needed for WBC number to recover back to normal level was 7 days. Upon administration of AP $5 \mathrm{mg} / \mathrm{kg}$ once daily, the WBC number could recover in 5-day period (Fig. 1).

Figure 1. Effects of Angelica sinensis polysaccharides (AP) treatment (given subcutaneously once daily) on white blood cell (WBC) number in cyclophosphamide (CY)-treated mice. CY was given subcutaneously $(200 \mathrm{mg} / \mathrm{kg})$ at day 0 and day 7 and AP was also injected subcutaneously once daily during the 14-day experimental period. Nor: Normal untreated group; NS: normal saline plus CY-treated group; AP5: AP $5 \mathrm{mg} / \mathrm{kg}$ plus CY-treated group, AP10: AP $10 \mathrm{mg} / \mathrm{kg}$ plus CY-treated group, AP25: AP 25 $\mathrm{mg} / \mathrm{kg}$ plus CY-treated group, respectively. "P $<0.001$ compared to Nor. ${ }^{\dagger} \mathrm{P}<0.05$, compared to NS.

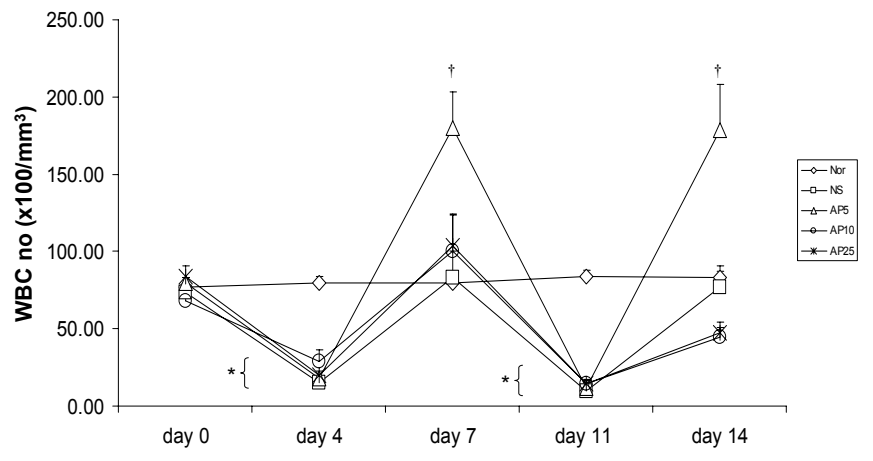

Figure 1

Figure 2. Effects of Angelica sinensis polysaccharides (AP) treatment (given subcutaneously once daily) on the blood vessel count in (A) gastric and (B) intestinal mucosae in cyclophosphamide (CY given subcutaneously $200 \mathrm{mg} / \mathrm{kg}$ )-treated mice. Nor: Normal untreated group. NS: normal saline plus CYtreated group. AP5: AP $5 \mathrm{mg} / \mathrm{kg}$ plus CY-treated group, AP10: AP $10 \mathrm{mg} / \mathrm{kg}$ plus CY-treated group, AP25: AP $25 \mathrm{mg} / \mathrm{kg}$ plus $\mathrm{CY}$-treated group, respectively. ${ }^{*} \mathrm{P}<0.05$, compared to Nor. ${ }^{\dagger} \mathrm{P}<$ 0.05 compared to the NS.

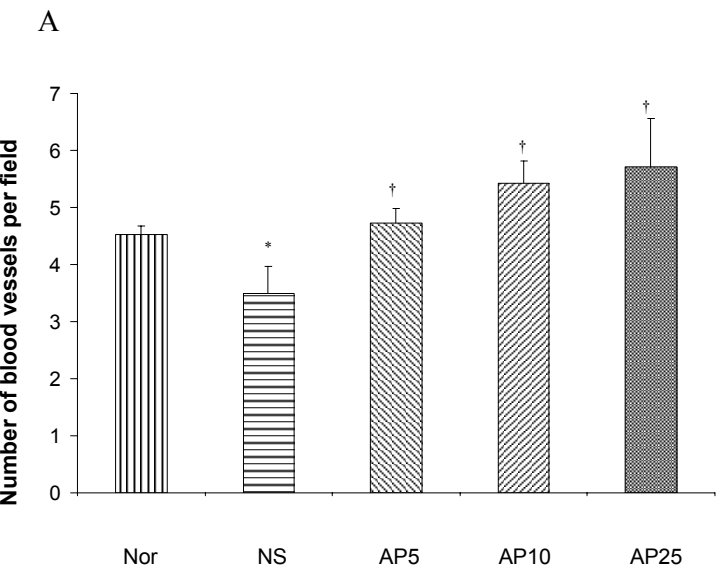

Figure 2

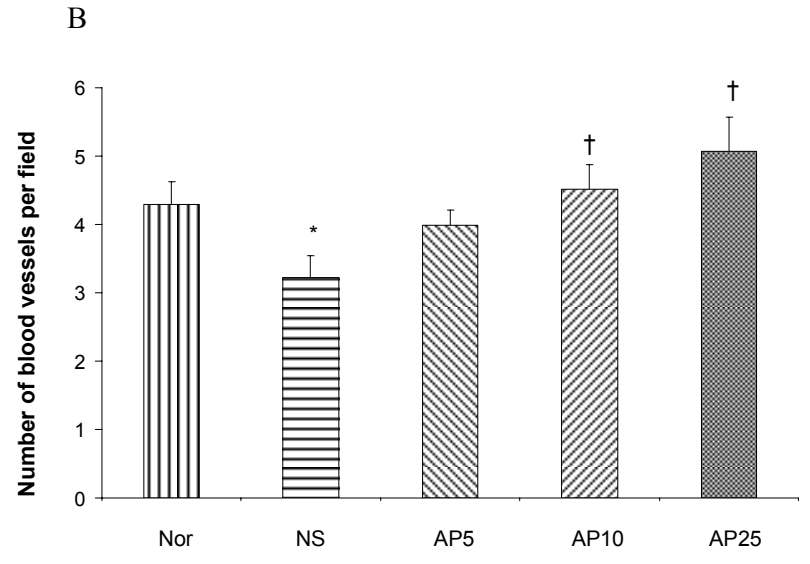

Figure 2

\section{Effects of Angelica polysaccharides on angiogenesis in gastric} and intestinal mucosae

CY administration significantly decreased the number of blood vessels in both the gastric (23\%, Fig. 2A) and duodenal $(25 \%$, Fig. 2B) mucosae. AP at the doses of 5, 10 and $25 \mathrm{mg} / \mathrm{kg}$ significantly increased the blood vessel count per field by $36 \%, 55 \%$ and $64 \%$ respectively in gastric mucosa. For duodenal mucosa, only AP 10 and $25 \mathrm{mg} / \mathrm{kg}$ had significant effects on blood vessel number (an increase of $40 \%$ and $57 \%$ respectively). Dose-dependent effect was observed in both gastric and duodenal tissues.

\section{Effects of Angelica polysaccharides on cell proliferation in gastric and duodenal mucosae}

Subcutaneous CY administration significantly decreased the number of proliferating cell by $48 \%$ in gastric (Fig. 3A) and by $74 \%$ (Fig. 3B) in duodenal mucosae. Concerning gastric mucosa, AP $5 \mathrm{mg} / \mathrm{kg}$ increased the proliferating cell number by $29 \%$ while there was a $154 \%$ and $208 \%$ increase in AP10 and AP25 group respectively when compared to NS group (Fig. 3A). Dose dependent effect was observed. Concerning duodenal mucosa, AP at the doses of 5 and $10 \mathrm{mg} / \mathrm{kg}$ significantly increased the proliferating cell count in duodenal mucosa by $131 \%$ and $305 \%$ respectively (Fig. 3B). AP $25 \mathrm{mg} / \mathrm{kg}$ however, led to an increase of only $93 \%$ when compared to the vehicle control group (Fig. 3B).

Effects of Angelica polysaccharides on VEGF, c-Myc, ODC and EGF protein expressions in gastric musoca

As we had demonstrated that both the blood vessel and proliferating cell counts in gastric and duodenal tissues were significantly affected by $\mathrm{CY}$ and AP treatments, the expression level of angiogenesis- and proliferation-related proteins were studied. CY significantly down-regulated the protein levels of VEGF, cMyc and ODC in the gastric mucosa (Fig. 4A, 4B and 4C respectively). There was a $73 \%$ decrease in the VEGF protein level and a $22 \%$ decrease in the c-Myc protein level in the corresponding NS group. A 52\% decrease in the expression level was noted in the ODC protein expression assay. In contrast, EGF expression was not altered (Fig. 4D). AP treatment only significantly reversed the dampening effect of CY on VEGF expression in a dosedependent manner (Fig. 4A). It was observed that AP 5 $\mathrm{mg} / \mathrm{kg}$ resulted in an increase of $75 \%$ while both AP 10 and $25 \mathrm{mg} / \mathrm{kg}$ doubled the increase in the VEGF protein 
expression. AP treatment did not have any effect on the expression of c-Myc, ODC and EGF in the gastric mucosa (Fig. 4B, 4C and 4D respectively).

Figure 3. Effects of Angelica sinensis polysaccharides (AP) treatment (given subcutaneously once daily) on the number of proliferation cells in (A) gastric and (B) duodenal mucosae in cyclophosphamide (CY) given subcutaneously $200 \mathrm{mg} / \mathrm{kg}$-treated mice. Nor: Normal untreated group. NS: normal saline plus CYtreated group. AP5: AP $5 \mathrm{mg} / \mathrm{kg}$ plus CY-treated group, AP10: AP $10 \mathrm{mg} / \mathrm{kg}$ plus CY-treated group, AP25: AP $25 \mathrm{mg} / \mathrm{kg}$ plus CY-treated group, respectively. $* p<0.05$, compared to Nor. ${ }^{\dagger} \mathrm{P}<0.05$ compared to NS.

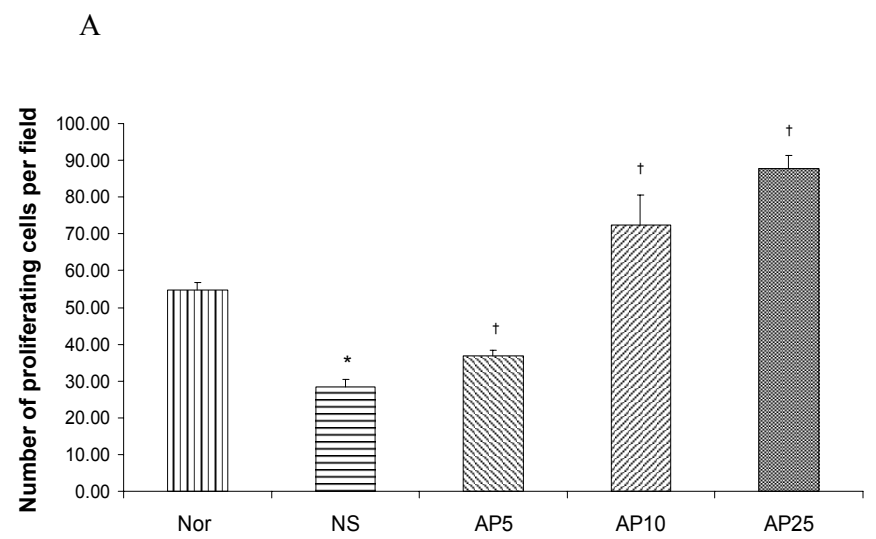

Figure 3

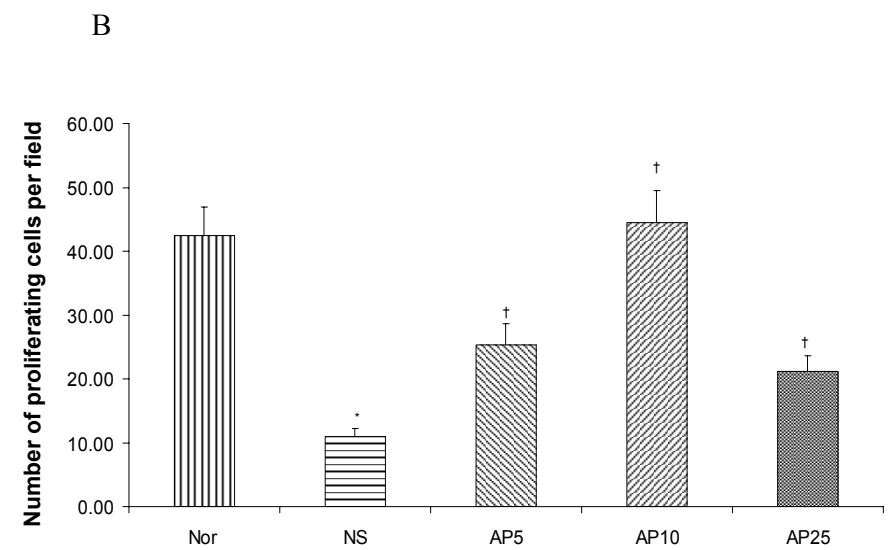

Figure 3
Figure 4. Effects of Angelica sinensis polysaccharides (AP) treatment (given subcutaneously once daily) on the protein expression (in terms of \% of change from control) of (A) vascular endothelial growth factor (VEGF), (B) c-Myc, (C) ornithine decarboxylase (ODC), and (D) epidermal growth factor (EGF) in the gastric mucosa in cyclophosphamide (CY given subcutaneously $200 \mathrm{mg} / \mathrm{kg}$ )-treated mice. Nor: Normal untreated group. NS: normal saline plus CY-treated group. AP5: AP 5 $\mathrm{mg} / \mathrm{kg}$ plus CY-treated group, AP10: AP $10 \mathrm{mg} / \mathrm{kg}$ plus CYtreated group, AP25: AP $25 \mathrm{mg} / \mathrm{kg}$ plus CY-treated group, respectively. ${ }^{*} \mathrm{P}<0.05$ compared to Nor. ${ }^{\dagger} \mathrm{P}<0.05$ compared to NS

A

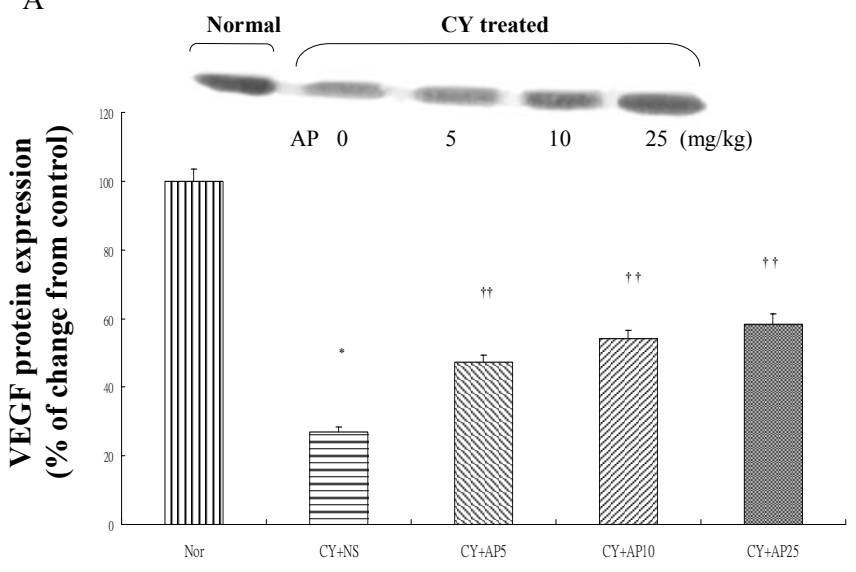

Figure 4

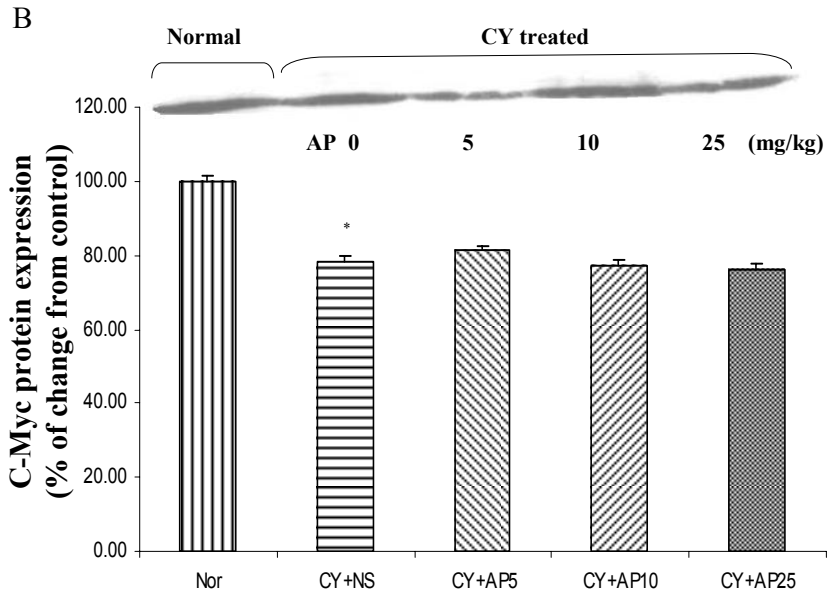

Figure 4 


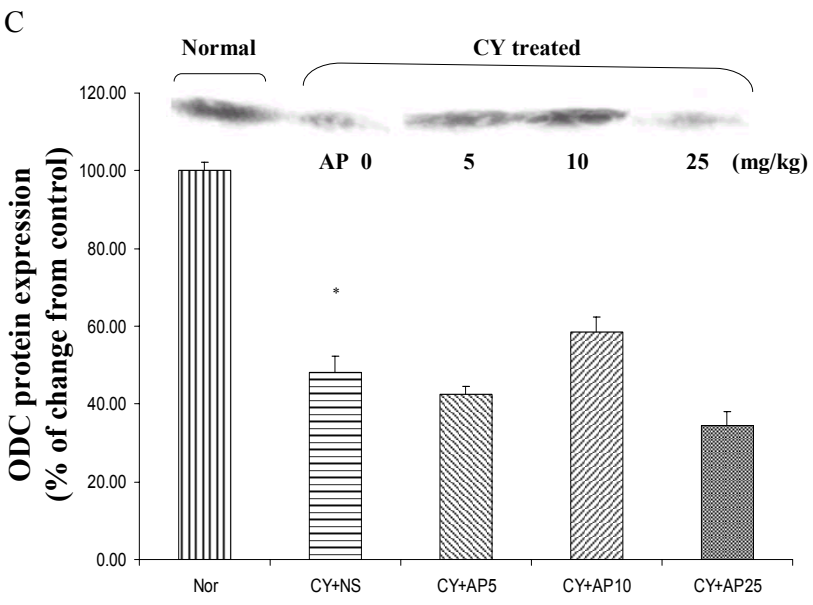

Figure 4

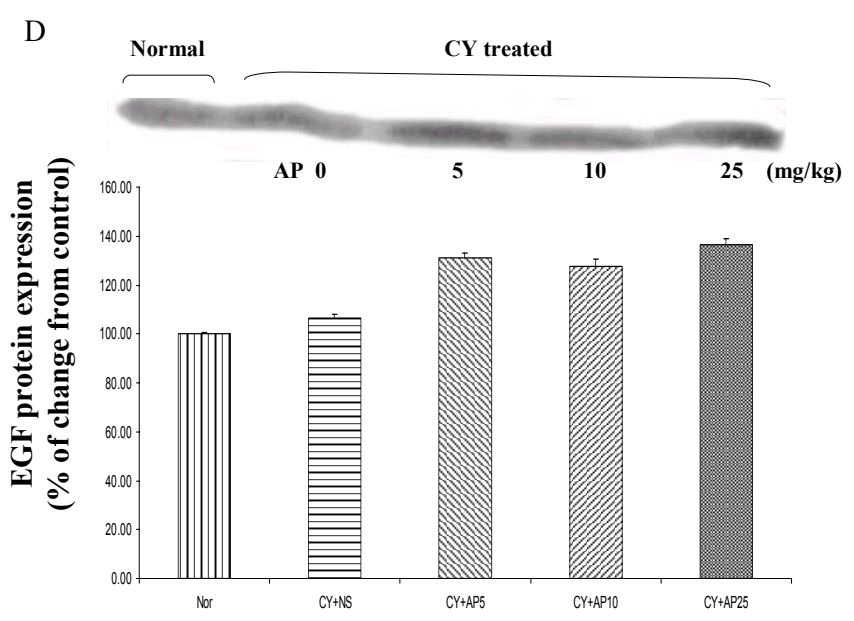

Figure 4

\section{Discussion}

In this study, CY produced myelosuppression manifested as leukopenia (Fig. 1). It also significantly reduced the blood supply and proliferating cell number in both the gastric and duodenal mucosae. Subcutaneous administration of AP at the dose of $5 \mathrm{mg} / \mathrm{kg}$ daily significantly promoted the recovery rate of immune system in mice in a 14-day treatment (Fig. 1). It also significantly increased the number of blood vessel and PCNA-positive cell in both the gastric (Fig. 2A and 2B respectively) and duodenal tissues (Fig. 3A and 3B respectively). Dosedependent effects were observed in general. Western blot analysis implicated the reduction by $\mathrm{CY}$ and normalization by AP of blood vessel count was VEGF dependent in gastric tissue (Fig. 4A). On the other hand, the decrease in proliferating cell number in gastric mucosa by $\mathrm{CY}$ administration was found to be c-Myc and ODCdependent (Fig 4B and $4 \mathrm{C}$ respectively).

$\mathrm{CY}$ is the non-cytostatic drug that acts non-specifically on both tumor cells and normal healthy cells with high proliferating capacity like immune cells and GI tissues. It exerts its cytotoxic effect via transfer of its alkyl groups to DNA, leading to cell cycle arrest and apoptosis. The major site of alkylation within the DNA is the N7 position of guanine. Alkylation of guanine results in depurination by excision of guanine residues, causing DNA strand breakage through scission of the sugar-phosphate backbone [3]. Patients under chemotherapeutic regimen are often subject to leukopenia which greatly increases the chance of opportunistic infections. As a result drug-free period is routinely introduced during regimen to prevent any or even fetal infections. In this model, we showed that 7 days were needed for the CY-treated mice to restore their immunity to normal level as indicated by WBC count. Such a long drug-free period is indeed undesirable because it allows the restoration of tumor tissue into active proliferating stage [2], as vascular endothelial cells can proliferate again and tumor will be nourished by supply of nutrients and oxygen. However, in mice treated with AP $5 \mathrm{mg} / \mathrm{kg}$, it was observed that a 5-day drug free period was enough to fully restore their normal immune response (Fig. 1). The present findings suggest that AP has immunostimulatory effect which can accelerate the recovery from leukopenia induced by $\mathrm{CY}$ and thereby shortens the drug-free period to allow a more frequent administration of anticancer drug e.g. CY so as to increase the efficacy of chemotherapy. In previous studies, AP has been shown to activate polyclonal B cells [20], induce interferon [21] and also activate helper $\mathrm{T}$ cells [22]. Lymphocyte proliferation assays, e.g. mitogen-mediated lymphocyte proliferation test and mixed lymphocyte culture also proved that AP could increase the rate of lymphocyte proliferation in vitro [23]. Oral administration of You-Gui-Wan, a classical prescription of TCM containing $\mathrm{AP}$, was shown to protect mice against hydrocoticoid-induced inhibition of IFN- $\gamma$, IL-2, IL-4 and IL-10 transcription [24]. In addition, vitamin B12, folinic acid and biotin identified in AP may also contribute to stimulated hematopoiesis [25]. All of these results are consistent with the present findings that $\mathrm{AP}$ is a tonic to hematopoietic system.

Concerning angiogenesis, it is believed that one of the anti-tumor mechanisms of $\mathrm{CY}$ is through the suppression on endothelial cell growth in tumor bed [26]. In addition, the down-regulation of VEGF by CY has been shown to be due to p53 activation [27]. This would decrease the blood supply to cancer cells so as to reduce nutrients and oxygen to support the growth and differentiation of tumor. However, it would also adversely affect the repairing capacity and the defensive mechanism of the GI mucosae that have been damaged during chemotherapy. In this regard, $\mathrm{AP}$ was shown to be beneficial to cancer patients because it normalized blood vessel number, which could probably supply more nutrients and oxygen to gastric and duodenal mucosae. This also promoted the defensive mechanism and also the repairing capacity of the GI system which has been damaged by $C Y$ administration. However, it should be noted that AP might also have a similar effect on the vascular endothelial cells in tumor bed, of which the proliferation and differentiation would be enhanced with a good supply of blood flow. Whether or not AP could affect blood vessels in tumors remains unknown. In this regard, further studies are needed to clarify this phenomenon.

CY exerts its cytotoxicity by cross-linking DNA strands and activation of p53-dependent growth arrest and apoptosis [28]. It was therefore not surprising that $\mathrm{CY}$ administration resulted in a decrease in the proliferating cell number in both the gastric and duodenal tissues. Indeed the decrease in cell proliferation in gastric tissue was supported by the down-regulation of c-Myc and ODC protein in the Western Blot analysis (Fig. 4B and 4C). It has been reported that p53 activation suppresses the transcription of c-Myc, an immediate early gene related to 
cell proliferation in which mitogenic stimulation leads to increased expression and drives the cell cycle from $G_{0}$ to $G_{1}$ [27]. Furthermore, c-Myc is known to induce the transcriptional activity of ODC gene [29], which is involved in polyamine synthesis. It is likely that the cell cyclearresting action of $\mathrm{CY}$ in the stomach in this study was due to the activation of p53 and therefore leading to the suppression of the c-Myc/ODC pathway. All these findings could explain the mechanism of $\mathrm{CY}$ on repression of cell proliferation in the gastroduodenal mucosae. In general, dose-dependent effect on the reversal action of AP on this suppressive effect could be observed. Although our previous study has shown that ODC was involved in APinduced normal gastric epithelial cell proliferation [10], the increased proliferating rate in this study was independent of the c-Myc, ODC or EGF as indicated by the corresponding protein levels in Western Blot analysis. However this could be partly contributed to the effect of AP on angiogenesis that increased the blood supply to tissues for growth and repairment.

To conclude, the above findings not only provide a fundamental insight into the mechanism of CY-induced systemic cytotoxicity, particularly in the gastrointestinal system, but also propose a role for polysaccharides from Angelica sinensis as a cytoprotective agent to spare the hemopoietic and gastrointestinal toxicities of CY. Whether or not the present study can be translated into practical benefits, warrants further investigation.

\section{Acknowledgments}

This study is supported by the Research Grants Council of Hong Kong (HKU 7397/03M) and the University of Hong Kong.

\section{Conflict of interests} exists.

The authors have declared that no conflict of interest

\section{References}

1. Ahmed AR, Hombal SM. Cyclophosphamide (Cytoxan). A review on relevant pharmacology and clinical uses. J Am Acad Dermatol 1984; 11: 1115-26.

2. Browder T, Butterfield CE, Kraling BM, Shi B, Marshall B, O'Reilly MS, Folkman J. Antiangiogenic scheduling of chemotherapy improves efficacy against experimental drug-resistant cancer. Cancer Res 2000; 60: 1878-86.

3. Hill DL. A Review of Cyclophosphamide. Springfield, II: Charles C Thomas, 1975.

4. Hesketh PJ. Comparative review of $5-\mathrm{HT}_{3}$ receptor antagonists in the treatment of acute chemotherapy-induced nausea and vomiting. Cancer Invest 2000; 18: 163-73.

5. Hardy ML. Herbs of special interest to women. J Am Pharm Assoc (Wash) 2000; 40: 234-42.

6. Mei QB, Tao JY, Zhang HD, Duan ZX, Chen YZ. Effects of Angelica sinensis polysaccharides on hemopoietic stem cells in irradiated mice. Acta Pharmacologica Sinica 1988; 9: 279-82

7. Cho CH, Mei QB, Shang P, Lee SS, So HL, Guo X, Li Y. Study of the gastrointestinal protective effects of polysaccharides from Angelica sinensis in rats. Planta Med 2000; 66: 348-51.

8. Ye YN, Koo MW, Li Y, Matsui $\mathrm{H}$, Cho $\mathrm{CH}$. Angelica sinensis modulates migration and proliferation of gastric epithelial cells. Life Sci 2001; 68: 961-8.

9. Ye YN, So HL, Liu ES, Shin VY, Cho CH. Effect of polysaccharides from Angelica sinensis on gastric ulcer healing. Life Sci 2003; 72: $925-$ 32.

10. Ye YN, Liu ES, Shin VY, Koo MW, Li Y, Wei EQ, Matsui H, Cho CH. A mechanistic study of proliferation induced by Angelica sinensis in a normal gastric epithelial cell line. Biochem Pharmacol 2001; 61: 1439-48.
11. Shang P, Qian AR, Yang TH, Jia M, Mei QB, Cho CH, Zhao WM, Chen ZN. Experimental study of anti-tumor effects of polysaccharides from Angelica sinensis. World J Gastroenterol 2003; 9: 1963-7.

12. Tsai NM, Lin SZ, Lee CC, Chen SP, Su HC, Chang WL, Harn HJ. The antitumor effects of Angelica sinensis on malignant brain tumors in vitro and in vivo. Clin Cancer Res 2005; 11: 3475-84.

13. Shang P, Mei QB, Cho CH. Analysis of Angelica polysaccharides constituents by high-performance liquid chromatography. Chung Kuo Yao Hsueh Tsa Chih 2000; 35: 332-35.

14. Alsop RM, Vlachogiannis GJ. Determination of the molecular weight of clinical dextran by gel permeation chromatography. J Chromatogr 1982; 246: 227-40.

15. Dubois M, Gilles KA, Hamiltion JK, Rebers PA, Smith F. Colorimetic method for determination of sugar and related substances. Anal Chem 1956; 28: 350-56.

16. Dische Z. A new specific color reaction of hexuronic acids. J Biol Chem 1947; 167: 189-98.

17. Read Sm, Northcote DH. Minimization of variation in the response to different proteins of the Coomassie blue $\mathrm{G}$ dye-binding assay for protein. Anal Biochem 1981; 116: 53-64

18. Augustin HG, Braun K, Telemenakis I, Modlich U, Kuhn W. Ovarian angiogenesis. Phenotypic characterization of endothelial cells in a physiological model of blood vessel growth and regression. Am J Pathol 1995; 147: 339-51.

19. Kitajima T, Okuhira M, Tani K, Nakano T, Hiramatsu A, Mizuno T, Inoue $\mathrm{K}$. Cell proliferation kinetics in acetic acid-induced gastric ulcer evaluated by immunohistochemical staining of proliferating cell nuclear antigen. J Clin Gastroenterol 1993; 17 (Suppl 1): S116-20.

20. Hinoko H. Recent research on Oriental medicinal plants. Econ Medic Plant Res 1985; 1: 53-85.

21. Noe J. Angelica Sinensis: A monograph. J Naturopath Med 1997; 7: 66-72.

22. Yoshiro K. The physiological action of Tang Quai and Cnidium. Bull Orient Healing Arts Instit USA 1985; 10: 269-78.

23. Wilasrusmee C, Kittur S, Siddiqui J, Bruch D, Wilasrusmee S, Kittur DS. In vitro immunomodulatory effects of ten commonly used herbs on murine lymphocytes. J Altern Complement Med 2002; 8: 467-75.

24. Yao C, Wang L, Cai S, Wei H, Zhou X, Wang H, Tian Z. Protective effects of a Traditional Chinese Medicine, You-Gui-Wan, on steroidinduced inhibition of cytokine production in mice. Int Immunopharmacol 2005; 5: 1041-8.

25. Huang KC. The Pharmacology of Chinese Herbs. 2nd ed. Boca Raton, FL: CRC Press; 1999.

26. Kerbel RS. Inhibition of tumor angiogenesis as a strategy to circumvent acquired resistance to anti-cancer therapeutic agents. Bioassays 1991; 13: 31-6.

27. Fang J, Xia C, Cao Z, Zheng JZ, Reed E, Jiang BH. Apigenin inhibits VEGF and HIF-1 expression via PI3K/AKT/p70S6K1 and HDM2/p53

FASEB J 2005; 19: 342-53.

28. Moallem SA, Hales BF. The role of p53 and cell death by apoptosis and necrosis in 4-hydroperoxycyclophosphamide-induced limb malformations. Development 1998; 125: 3225-34.

29. Bouchard C, Thieke K, Maier A, Saffrich R, Hanley-Hyde J, Ansorge W, Reed S, Sicinski P, Bartek J, Eilers M. Direct induction of Cylin D2 by myc contributes to cell cycle progression and sequestration of p27. EMBO J 1999; 18: 5321-31. 